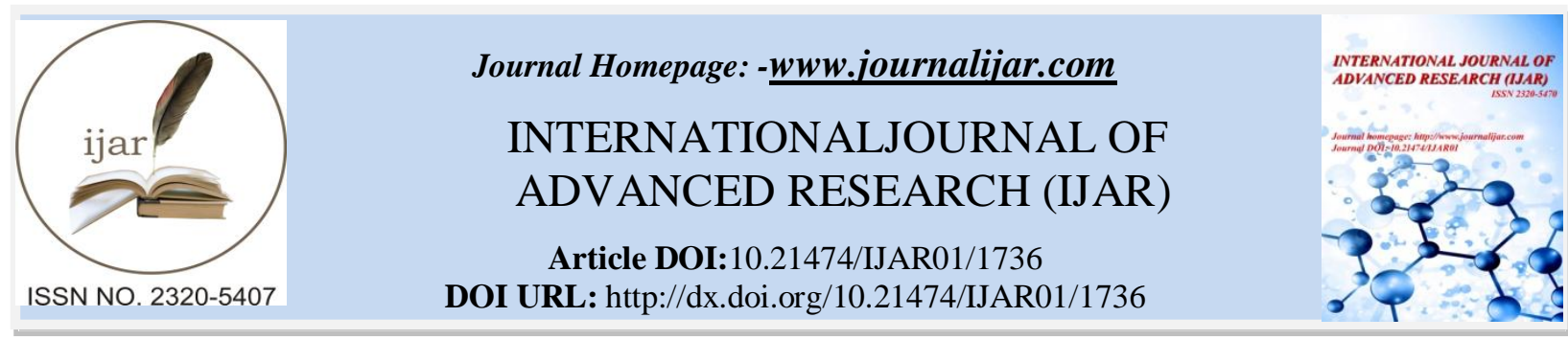

RESEARCH ARTICLE

\title{
Analysis of Smallholder Farmer's Adoption and ContinuedApplication of Teff Row Planting Technique inWolaita Zone, Southern Ethiopia.
}

\author{
Geremew Kefyalew ${ }^{1}$, Abdi Bedilu ${ }^{1}$, Muzeyin Ahmed ${ }^{2}$ and Workineh Mena ${ }^{2}$. \\ 1. Wolaita Sodo University, College of Business and Economics, Ethiopia. \\ 2. Wolaita Sodo University, College of Natural and Computational Sciences, Ethiopia.
}

\section{Manuscript Info \\ Manuscript History \\ Received: 12 July 2016 \\ Final Accepted: 19 August 2016 \\ Published: September 2016 \\ Key words:- \\ Adoption, Row Seeding, Continued \\ Application, Teff, Smallholders, \\ Bivariate Probit model, Wolaita Zone.}

\begin{abstract}
Ethiopian economy continued to be leaded by agriculture sector in which smallholder farmers in turn dominate the sector. This fact implies that if transformation of the country's economy is needed, transforming the smallholder sector is the base and the key. Improving and developing new farming technology is one among such transformation tools and pathways. In this regard, the latest farming strategy recommended for smallholder farmers in the country is the so called "Row Seeding." This studywas aimedat analyzing factors determining and influencing smallholder farmer's adoption and continuous application of teff row planting method in Wolaita zone. The study was based on survey data collected from 300 farming households and bivariate probit model was employed to analyze the issue. Household level human capital, household asset endowment, farm level institutional factors and policy variables significantly influence farmers' decisions to adopt teff row seeding techniqueand its continued application in Wolaita zone, southern Ethiopia. Other supporting technology should be developed to ensure the sustainability of the technique in the study area.
\end{abstract}

Copy Right, IJAR, 2016,. All rights reserved.

\section{Introduction:-}

\subsection{Background of the Study:-}

Ethiopian economy continued to be leaded by agriculture sector in which smallholder farmers dominate the sector in turn. This implies that if continued growth of the sector is needed, the base is growth and development of the smallholder farmers for which farming activity represent the major livelihood strategy for those smallholder farmers. Improving and developing new farming strategy/technique is the base for such transformations. According to (Minten and Barrett, 2008), one effective way to increase agricultural productivity is possible through wider adoption ofnew farming technologies by smallholder farmer's. In Ethiopia, the latest farming technique advised for smallholder farmers was the one called "Row Seeding Technique," to replace the previously used broadcasting technique to sow crops like teff in the country.Teff is a small cereal grain indigenous to Ethiopia and the chief element in the diet of most Ethiopians.However, what matter is how smallholder's farmers decideto accept and apply or reject the newly recommended farming techniques at household level. This study aims to analyze factors 
determining and influencing smallholder farmer's adoption and intensive use of teffrow-seeding method in Wolaita zone.

\subsection{Rationale of the Study:-}

Literatures indicates that only few farmers adopt new farming technology as soon as the technology was announced (Tura et al, 2010, Regessa et al. 2013). In Ethiopia, despite large efforts that have been made to broadcast new farming technologies in different parts of the country, the decision of smallholder farmers to adopt vary widely across different agro-ecologies and within the same agro-ecology based on various technical and non-technical factors affecting and determining their decision.

As evidenced with few empirical works in sub-Saharan countries some of the factors affecting technology adoption are assets, income, institutions, vulnerability, awareness, innovativeness by smallholder farmers, access to agricultural advisory services, access to rural credit and being member of agricultural associations ,age, family size, farming experience (Uaiene, R. N., 2006, G. Dehinenetet al., 2014,). Eventhough empirical studies have identified different factors that affect adoption of new farming technology in Ethiopia, most of the study where undertaken in general and conducted in different areas of the country. As far as the study area is concerned little is known about factors influencing and determining smallholder farmer's adoption of row seeding technology and itscontinued application in Wolaita zone.For policy design andpurposeful intervention, information on the extent of adoption of disseminated new farming technologies - such as row seeding, understanding of socio-economic, technical and institutional factors determining adoption of such practices in the study area would worth imperative to analyse.Therefore, this study was undertaken to identify the determinants of the teff row planting technology adoption and its sustainably using the method by smallholder farmersinWolaita zone, southern Ethiopia.

Accordingly, the primary objective of this study was to analyze factors determining the adoption and intensive use of teff row seeding technique in Wolaita zone. More specifically the current study was designed to identify factors determining adoption of row teff seeding technology and aims at assessingfactors that affect itscontinued application in the study area.

\section{The Study Setting:-}

\subsection{Data:-}

The primary source of data for this study was a survey conducted on sampled 300 smallholder farmers from five districts of Wolaita zone betweenMarch and April of 2015. To contact these sampled farmers, we employed a multi-stage sampling technique where in the first stage 5 districts of the zone were selected purposelybased on their teff production potential (Wolaita Zone Agriculture office, 2015). Then Farmers' Associations (FAs) with great teff productivity potential were identified from each districts. In the second stage, FAs were selected randomly from each districts according to their proportion. In the third stage, a total of 300 farmers were selected using probability proportional to sample size. Finally survey questionnaire was developed and used to collect the necessary data from sampled smallholder farmers. Then, experienced enumerators (experts in the field) were recruited and trained to facilitate the task of data collection under supervision of the researchers.

\subsection{Conceptual Framework of the study:-}

Doss (2006) define an adopter as a farmer who adopted a component or more of a new technology and continuously using it, whereas non-adopters are those who have never tried a technology. Defining adoption in this way suggests that once farmers applied a technology, they will keep applying it in the next time. In many cases, however, it is common that smallholder farmers might try a new technology and decide to (or not to) continue using the system in the respective years. In this context, adopters as farming households that have applied teffrow seeding of technique at least once over recent years for this particular study. Thus, we consider smallholder farmers as an adopter if he/she applied the technology every season since the time he or she first adopted it. This idea simply implies that, the adoption of new farming technology and its continued use are the results of interdependent and sequential decisions (Tura et al., 2010).

The decisions of smallholder farmers to apply and sustainteff row seeding techniques are only relevant for those who tried it. Here, the two major decisions by those farmers are-to apply the technique and then sustain it in the next cropping season - can be technically analyzed by employing some statistical models such as logit or probit models. However, according to (Tura et al. 2010)such a specification might result in ineffective parameter estimation as it may fail to the possible correlations among the two decisions. This is said because of the fact that 
continuation decision is succeeded by application decisions. For this matter, such issues of smallholder decisions could easily be undertaken by the bivariate probit model (Wooldridge, 2002; Greene, 2012). This bivariate probit model appears in both the adoption decision and sustaining the application in thenext cropping season(s).

\subsection{Specification of Empirical Model: Bivariate probit model:-}

According to (Carletto et al., 1999), the farmers decides to discontinue an application of any modern farming technology in a given year if and only if it reduce the area planted with the once adopted technology to zero.In the ordinary probit model, there is only one binary dependent variable $\mathrm{Y}$ and so only one latent variables $\mathrm{Y}^{*}$ is used. In contrast, in the bivariate probit model there are two binary dependent variables $Y_{1}$ and $Y_{2}$, so there are two latent variables: $\mathrm{Y}_{1}{ }^{*}$ and $\mathrm{Y}_{2}{ }^{*}$. According to (Green , 2012), it is assumed that each observed variable takes on the value 1 if and only if its underlying continuous latent variable takes on a positive value:

with

$$
\begin{aligned}
& \mathrm{Y}_{1}=\left\{\begin{array}{l}
1, \text { if } \mathrm{Y} 1 *>0 \\
0, \text { otherwise }
\end{array}\right. \\
& \mathrm{Y}_{2}=\left\{\begin{array}{l}
1, \text { if } \mathrm{Y} 2 *>0 \\
0, \text { otherwise }
\end{array}\right.
\end{aligned}
$$

and

$$
\left\{\begin{array}{l}
\gamma 1 *, X 1 \beta 1+\varepsilon 1 \\
\gamma 2 *, X 2 \beta 2+\varepsilon 2
\end{array}\right.
$$

$$
\left(\begin{array}{l}
\varepsilon 1 \\
\varepsilon 2
\end{array}\right) \backslash X \sim \mu\left(\begin{array}{l}
0 \\
0
\end{array}\right),\left(\begin{array}{ll}
1 & p \\
p & 1
\end{array}\right)
$$

where:

$\mathbf{Y}_{1}^{*}$ and $\mathbf{Y}_{2}^{*}$ are underlying latent variables

$\mathbf{Y}_{1}=\mathbf{1}$, if sampled farmers adopt and applied row seeding technique to plant teff, 0 otherwise (Never applied the technique at the time of survey).

$\mathbf{Y}_{2}=\mathbf{1}$, if sampled farmers adopt and continuously applied teff row seeding technique, 0 otherwise (Applied the technique once but discontinued it at the time of survey).

$\boldsymbol{\beta} \mathbf{1}$ and $\boldsymbol{\beta} 2$ are vectors of estimation parameters to be computed.

$\mathbf{X}_{\mathbf{1}}$ and $\mathbf{X}_{\mathbf{2}}$ are list of explanatory variables enterer into the estimation model.

$\boldsymbol{\varepsilon} \mathbf{1}$ and $\boldsymbol{\varepsilon} \mathbf{2}$ are normally distributed error terms.

Fitting the bivariate probit model involves estimating the values of $\beta 1, \beta 1$ and $\rho$. To do so, the likelihood of the model has to be maximized. This likelihood is:

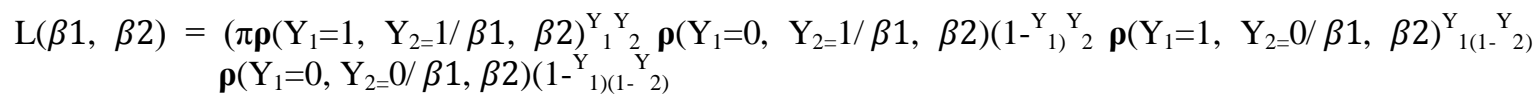

Substituting the latent variables $Y_{1}{ }^{*}$ and $Y_{2}{ }^{*}$ in the probability functions and taking logs gives:

$$
\begin{aligned}
\sum Y 1 Y 2 \ln \rho(\varepsilon 1 & >-X 1 \beta 1, \varepsilon 2>-X 2 \beta 2)+(1-Y 1) Y 2 \ln \rho(\varepsilon 1<-X 1 \beta 1, \varepsilon 2) \\
& >-X 2 \beta 2)+(1-Y 1)(1-Y 2) \ln \rho(\varepsilon 1<-X 1 \beta 1, \varepsilon 2<-X 2 \beta 2)
\end{aligned}
$$

After some rewriting, the log-likelihood function becomes:

$$
\begin{gathered}
\sum Y 1 Y 2 \ln \Phi(X 1 \beta 1, X 2 \beta 2, \rho)+(1-Y 1) Y 2 \ln \Phi(-X 1 \beta 1,-\rho)+(1-Y 1)(1 \\
-Y 2) \ln \Phi(-X 1 \beta 1,-X 2 \beta 2, \rho)
\end{gathered}
$$


From the last equation $\Phi$ is the cumulative distribution function of the bivariate normal distribution. Similarly $Y_{1}$ and $Y_{2}$ in the log-likelihood function above are observed variables being equal to one or zerodepending on the farmer's decision regarding adoption of the technique as well as continuously apply the technique once adopted.

It is clear that, for a given farm household $\mathbf{Y}_{\mathbf{1}}$ is not observable unless $\mathbf{Y}_{\mathbf{2}}=\mathbf{1}$. In our case, this implies that possibly we may have three different observations for each farm households which can be summarized as follows:

$$
\begin{aligned}
& y_{2}=0: \operatorname{prob}\left(y_{2}=0\right)=1-\Phi\left(\beta_{2}^{\prime} X_{2}\right) \\
& y_{1}=0, y_{2}=1: \operatorname{prob}\left(y_{1}=0, y_{2}=1\right)=\Phi_{2}\left(-\beta_{1}^{\prime} X_{1}, \beta_{2}^{\prime} X_{2},-\rho\right) \\
& y_{1}=1, y_{2}=1: \operatorname{prob}\left(y_{1}=1, y_{2}=1\right)=\Phi_{2}\left(\beta_{1}^{\prime} X_{1}, \beta_{2}^{\prime} X_{2}, \rho\right)
\end{aligned}
$$

Where $\Phi($.$) denotes the univariate standard normal cumulative distribution function (CDF), and \Phi_{2}($.$) denotes the$ bivariate standard normal CDF. This three observations implies that the total samples are going to be categorized into three sub-samples: Farmers not totally applying the row seeding technique, those who applied once but discontinued in the consecutive crop seasons and those who applied and keep applying the technique in the next times (cropping seasons).

\section{Results and Discussion:-}

\subsection{Descriptive statistics:-}

After necessary statistical test was made the data was analyzed using STATA version 13.The survey data revealed that only $23.33 \%$ of the sample households have never applied teff row seeding technology in the study area since it introduction. About $76.67 \%$ of the sampled households have reported they applied teff row seeding technique as a new farming technology (see Table 1). About 67.33 percent of sampled smallholder farmers reported they continued application of the row planting of teff crop once they started applying the technique. The remaining 32.67 percent of the sampled farmers replied they discontinue the technique.

Table 1: Adoption of teff row seeding technology in Wolaita zone

\begin{tabular}{|l|l|l|}
\hline Sampled smallholder farmers & Frequency & Percent \\
\hline Adopters & 79 & $23.33 \%$ \\
\hline Non-Adopters & 221 & $76.67 \%$ \\
\hline Total & 300 & \\
\hline
\end{tabular}

Source: survey result, 2015

Those households which discontinued applied row seeding technique were asked to list the reasons why they could not continue applying the technology. Most farmers (67.35\%) identified that the new planting technique requires much labour at the time of planting. This is due to the fact that teff seed very small in size and to plant it in row, it takes time and consume many daily labour. The traditional teff planting which is called broadcasting can be done only by one person. Thus the sampled farmers pointed out that compared to the traditional one, planting teff in row is very difficult part, even if it saves seed in a greater amount. Another major factor that sampled smallholder farmers mentioned as a reason to discontinue the technique isthat there is lack of enough plots of land to continuously apply the method. About $45.87 \%$ of the respondents reason out this factor (See Table 2). This justifiable that there is a shortage of land in the zone and to apply the technique requires more plot of land, to prepare the land in advance.

Table 2: Sustaining teff row seeding technology in Wolaita zone

\begin{tabular}{|l|l|l|}
\hline Sampled smallholder farmers & Frequency & Percent \\
\hline Discontinued the technology & 96 & $32.67 \%$ \\
\hline Continuously applied the technology & 204 & $67.33 \%$ \\
\hline Total & 300 & \\
\hline
\end{tabular}

Source: Survey result, 2015 


\subsection{Econometric Estimation Results and Discussions:-}

\subsubsection{Factors Determining Adoption of teff row seeding technique in Wolaita Zone:-}

As described above the bivariate probit model was selected and applied to analyse factors affecting teff rowseeding techniqueapplication and factors that determine its continued use in Wolaita zone. Before presenting the model we tested against the other models. The test result revealed the model was fit for the estimation. The estimation result showed that man equivalent, land size owned by the household measured in timad, farming experience and tropical livestock unit have positively and significantly influence the decision to adopt and apply row seeding of teff in Wolaita zone. However, farming experience of the household head was found to affect significantly the decision to adopt the technology negatively (See Table 3).

Table 3: Estimation results on factors influence adoption of teff row seeding technique in Wolaita Zone

\begin{tabular}{|l|l|l|l|l|}
\hline Variables/Factors & Coefficients & Standard error & $\mathbf{Z}$-value & $\mathbf{P}>\mathbf{Z}$ \\
\hline Sex of Household head & 0.4223864 & 0.2845678 & 1.48 & 0.138 \\
\hline Age of household head & 0.0380931 & 0.0281273 & 1.35 & 0.176 \\
\hline Man equivalent & $0.3379441^{* *}$ & 0.1542151 & 2.19 & 0.028 \\
\hline Farm Experience & $-0.0575154^{* *}$ & 0.0267917 & -2.15 & 0.032 \\
\hline Land size in timad & $0.2384619^{* * *}$ & 0.0711344 & 3.35 & 0.001 \\
\hline Number of plots & 0.0375569 & 0.2542565 & 0.15 & 0.883 \\
\hline Off-farm income & -0.0000396 & 0.0000401 & -0.99 & 0.324 \\
\hline TLU & $0.1047249^{* *}$ & 0.0499523 & 2.1 & 0.036 \\
\hline Access to credit & 0.2282398 & 0.2697119 & 0.85 & 0.397 \\
\hline Constant & -3.525141 & 0.963923 & -3.66 & 0.000 \\
\hline
\end{tabular}

$*, * *$, and $* * *$ indicates statistical significance of the coefficient result at $10 \%, 5 \%$ and $1 \%$ significance level respectively.

Source: Authors Computation from field survey, 2016

The estimation result revealed that man equivalent is one of the significant variable that influence the decision of smallholder farmers to apply or not to apply row planting of teff production in the study area. This implies that, the new farming technique (row seeding) requires additional family labour, especially in the time of planting (seeding). This is due to the fact that teff seed is a crop with a very small size which is difficult to plantin row and therefore, family labour measured in man equivalent is one important factor in determining the likelihood of applying the technique. Regarding the size of its seed in Wikipedia teff was explained as "The word "teff" is connected by folk etymology to the Ethio-Semitic root "țff", which means "lost" (because of the small size of the grain)".This finding indicates that teff sowing through row planting technique was very labour intensive practice demanding more man power compared to the traditional broadcasting technique.

Figure 1: Teff planted in broadcasting technique

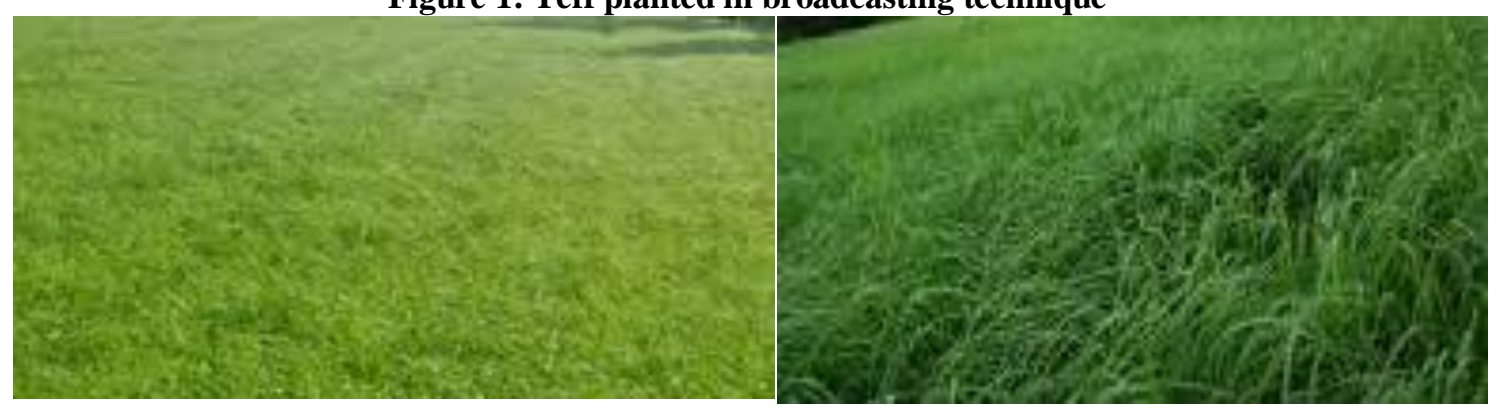


Figure 2: Teff planted in row

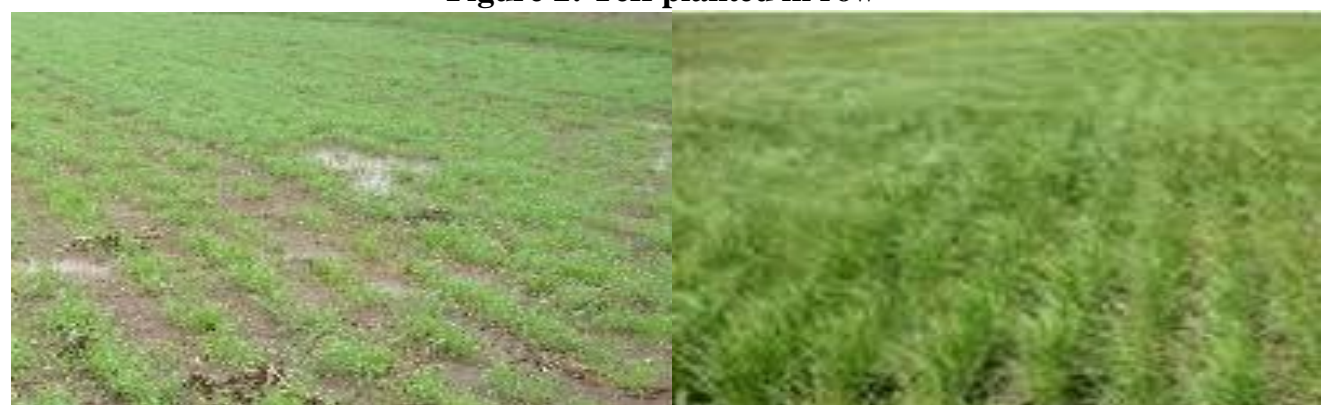

The other significant variable influencing the decision of farmers to apply the technique is the farm land holding size. The study result revealed that those farmers holding larger land size have a greater likelihood to apply the new teff planting technique. This is also reasonable because land size is the key farming variable to apply or not to apply any farming technology. Especially, Wolaita is one of the densely populated and where land is a key constraint zone in Ethiopia. Thus, land ownership is one of the significant variable to influence the farmer's decision toward application of the new teff seeding technique in the study area. Farming experience is also another significant factor that influence the decision of farmers to apply or not to apply the new teff planting technique in the study area. Farmers who have more experience are more likely to apply and use the new teff planting. This is in line with the general convention that experience is an important resource in any field. This study result support this fact. Livestock ownership measured in tropical livestock unit is another important and significant factor in influencing farmer's decision regarding adoption of the new farming mechanism in Wolaita zone.

\subsubsection{Factors Determining Continued Application of Teff Row Seeding Technique in Wolaita zone:-}

Identifying factors determining agricultural technology adoption by farming household was one of the researchable area for researchers and the key concern for policy makers in previous times. Currently, equal to adoption decisions the issue of sustaining the technology gets special concern for scholars and policy makers. Under this section, we discuss on the issues concerning factors determining farmer's decision to continue or not the newly applied farming technique in the study area. As described above about 32.67 percent among the sampled farmers reported that they discontinued application of row planting of teff reasoning different factors.

These factors are identified and discussed as follows. Among these factors sex of household head, adult equivalent, total land size owned, tropical livestock unit and number of trainings attended found to be positively and significantly influence the decision to sustainteff row seeding technique in Wolaita zone. However, household head's farming experience, number of plots owned and better access to off-farm income negatively and significantly influences the continued use of the specifiedteff sowing techniquein the study area (See Table 4). This study estimation result claim that those farmers headed by male households have more likely to continue application of row planting of teff in the study area compared to those headed by female households. This possibly linked with row sowing of teff requires preparation of land many times to apply the technique which requires more works. Adult equivalent also found to be statistically significant and have positive impact on the sustaining application of the technique. This is possibly interpreted as those farmers owning more adult equivalent workers in the family possess better likelihood to continue applying the technique. This finding was in line with the findings of Vandercasteelen et al (2014). Their study suggested that although a positive attitude and a belief in the yield improving potential of row sowing of teff, those farmers who applied once the technique only utilize a relatively small part of their plots in the next planting season which is mainly concerned with the additional labor requirement and possibly the need for more knowledge and experience with the new planting technique.This and our finding revealed that adult equivalent one major important factor in influencing farmer's decision to apply the technique and sustain the application in the study area. 
Table 4: Factors determining continued application of teff row seeding technique in Wolaita zone

\begin{tabular}{|l|l|l|l|l|}
\hline Variables/Factors & Coefficients & Standard Error & Z-value & P>z \\
\hline Sex of Household head & 0.6794 & 0.2422 & 2.8000 & 0.0050 \\
\hline Age of household head & $0.0172^{* *}$ & 0.0130 & 1.3300 & 0.1850 \\
\hline Man equivalent & $0.3596^{*}$ & 0.0882 & 4.0800 & 0.0000 \\
\hline Farm Experience & $-0.0384^{*} *$ & 0.0119 & -3.220 & 0.0010 \\
\hline Land size in timad & $0.0991^{*}$ & 0.0476 & 2.0800 & 0.0370 \\
\hline Number of plots & -0.8465 & 0.1715 & -4.930 & 0.0000 \\
\hline Off-farm income & $-0.0001^{* *}$ & 0.0000 & -2.140 & 0.0320 \\
\hline TLU & $0.0925^{*}$ & 0.0394 & 2.3500 & 0.0190 \\
\hline Access to credit & -0.2717 & 0.1850 & -1.470 & 0.1420 \\
\hline Number of trainings attended & 0.9362 & 0.2687 & 3.480 & 0.0000 \\
\hline Constant & -1.7071 & 0.4811 & -3.550 & 0.0000 \\
\hline /athrho & 13.36 & 663.22 & 0.0200 & 0.9840 \\
\hline
\end{tabular}

Source: Authors Computation from field survey, 2016

The other significant factor that determine continuity or discontinuity of teff row planting in Wolaita zone is that of tropical livestock unit and the number of training attended regarding row plaint by farmers. Those who have attended more trainings have a greater likelihood than their counterparts to continuously apply the technique in the study area. This is because as a new farming technology it requires continues training and practices to apply and sustain the technique. Tropical livestock unit was also another factor that affect sustainability the technique as it is a technology that requires more livestock asset, especially at the time of sowing the seed and to prepare the land for planting.Factors like household head's farming experience, number of plots owned and better access to off-farm income negatively and significantly influences the continued use of the specified teff sowing technique in the study area.

\section{Conclusions:-}

Currently, Ethiopia is searching and doing a promising ways to come out of poverty. In such efforts, widespread adoption of new farming technologies that can enhance agricultural production is paid special attention. Today, row seeding of major crops such as teff production is among the top new technology given priority and suggested for farmers at household level expecting increased productivity of the crops in the country. Constrained by many problems, however, adoption of such new technologies were not sufficient to meet this national need. Furthermore, the adopted technology should be sustainably applied to bring about the targeted goal and to evaluate its impact.

This study was designed to analyse factors that influence and determine this situation in Wolaita zone aiming towards understanding the process of post-adoption behaviour of smallholder farmer's households. The result from descriptive statistics revealed that even though many farmers have applied the technology once, majority of them failed to continue it. The sampled farmers reported that the technique was promising and increase productivity. It saves seed and save time at the time of collection and cleaning.However, many factors determine and constrain the application and sustainability of the technique in the study area. The finding from bivariate probit modelestimation demonstrates thatman equivalent, land size owned by the household measured in timad, and tropical livestock unit positively and significantly influence the decision to adopt and apply row seeding of teff in Wolaita zone. However, farming experience of the household head was found to affect significantly the decision to adopt the technology negatively. Furthermore, when dealing with factors affecting continued use of the technology, sex of household head, number of adult equivalent, total land size owned, tropical livestock unit and number of trainings attended by farmers found to be positively and significantly influences the intensive use of teff row planting in Wolaita zone. In this regard, household head's farming experience, number of plots owned and better access to offfarm income negatively and significantly influences the continued use of the specified technology in the study area.

\section{Recommendation and Policy Implications:-}

Appropriate strategic interventions that consider the above listed factors influencing the adoption and continued use of the techniqueare required so that teff row seeding technology can be adopted and continuously used to ensure smallholder household'sfarm yields as expected. The local government should also strength the extension system 
that needs to address the factors which affect the decision to use a technology continuously. In this regard, increasing the number of training and field visits should be given priority.In addition, another supporting technology should be developed to ensure the sustainability of the technique in the study area. For example, technology that can easily be applied by farmers should be developed to sow the crop, because at the planting time the new technique requires more daily labour.

\section{Acknowledgment-}

This research was granted by Wolaita Sodo University in year 2015 under Vice President for Research and Community Services. The University is one of the recently established government higher education institutions in Ethiopia, which were the results of the capacity building strategies undertaken by the Ministry of Education. The University is found atSodotown, which is around $315 \mathrm{KMs}$ away towards South from the capital Addis Ababa. Currently the university is serving in teaching, conducting problem solving researches and is providing different demand based services for local community. The authors would also like to thank an anonymous reviewer for the valuable comments given, which improved the content and presentation of the paper in manyways. We are also grateful to the experts who participated in the data collection process.

\section{References:-}

1. Cragg, J.G. (1971). Some statistical models for limited dependent variables with application to the demand for durable goods. Econometrica, 39, 829-844.

2. Cooper, J.C., \&Keim, R.W. (1996). Incentive payments to encourage farmer adoption of water quality protection practices.American Journal of Agricultural Economics, 78(1), 54-64.

3. Carletto C, de Janvry A, Sadoulet E (1999). Sustainability in the Diffusion of innovations: smallholder nontraditional agro-exports in Guatemala. Econ. Dev. Cult. Change, 47: 345-369.

4. Dehinenet G., H. Mekonnen, M. Kidoido, M. Ashenafi and E. GuerneBleich, (2014) Factors influencing adoption of dairy technology on smallholder dairy farmers in selected zones ofAmhara and Oromia National Regional States, Ethiopia

5. Doss CR (2006). Analyzing Technology Adoption Using Microstudies: Limitations, Challenges, and Opportunities for Improvement. Agric. Econ., 34: 207-219.

6. Gebregziabher, G., \& Holden, S. (2011). Does irrigation enhance and food deficits discourage fertilizer adoption in a risky environment? Evidence from Tigray, Ethiopia. Journal of Development and Agricultural Economics, 3(10), 514-528.

7. Greene, William H., Econometric Analysis, seventh edition, Prentice-Hall, 2012.

8. Moffatt, P.G. (2005). Hurdle models of loan default. Journal of the Operational Research Society, 56(9), 1063-1071.

9. Neill PS, Lee DR (2001). Explaining the adoption and disadoption of sustainable agriculture: The case of cover crops in Northern Honduras. Economic Dev. Cult. Change, 49(4): 793-820.

10. Regassa, C., Dankayi, A., Achemampona P., Wiridu A., Chapo-to A., Asamoah M., and Tripp R., "Patterns of adoption of improved maize technology in Ghana, Working paper 36/July 2013.Shiferaw, B.A., Kebede, T.A., $\&$ You, L. (2008). Technology adoption under seed access constraints and the economic impacts of improved pigeonpea varieties in Tanzania. AgriculturalEconomics, 39(3), 309-323.

11. Teklewold, H., Dadi, L., Yami, A., \& Dana, N. (2006). Determinants of adoption of poultry technology: A Double-Hurdle approach. Livestock Research for Rural Development, 18(3), Article \#40.

12. Saha A, Love HA, Schwart R (1994). Adoption of emerging technologies under output uncertainty. Am. J. Agric. Econ., 76 (4), 836-846.

13. Tura M, Aredo D., Tsegaye W., La Rovere, R, Tesfahun G., Mwangi W. and Mwabu G., "Adoption and continued use of improved maize seeds:Case study of Central Ethiopia", African Journal of Agricultural Research Vol. 5(17), pp. 2350-2358, 4 August, 2010.

14. Uaiene, Rafael N, (2006), Determinants of Agricultural Technology Adoption in Mozambique,

15. International Food Policy Research Institute

16. Vandercasteelen, J., M. Dereje, B. Minten, and A.S. Taffesse. 2014. Perceptions, Impacts and Rewards of Row Planting of Teff. ESSP Research Note 33. Addis Ababa: IFPRI. 